\title{
Research With a Twist: Podcast Pairs Insights with Beer, Wine and Spirits
}

\author{
Jeffrey York (University of Colorado Boulder)
}

KEYWORDS: Entrepreneurship, Startups.

Sitting at a local brewery with Brad Werner (https://www.colorado.edu/business/leeds-

directory/faculty/brad-werner) , my colleague at Leeds School of Business at the University of Colorado Boulder, I was excited to dive into a white paper on advancing entrepreneurship research through metaanalysis. On the table before us sat a microphone and a dozen glasses of craft beer.

We were recording the latest episode of "Creative Distillation," a podcast about entrepreneurship research (https://www.colorado.edu/business/deming/news-

stories/creative-distillation-research-podcast) that's produced by the Deming Center for Entrepreneurship at Leeds. Together, Brad and I distill recent studies into actionable insights that business students and the broader startup community can use.

The nexus for the podcast emerged from my conversations with Brad, an instructor and the teaching director for the Deming Center, about the value of entrepreneurship research-and how challenging it can be for entrepreneurs to extract something they can use. So, together with the help of guest researchers from around the globe, we spend each episode breaking down a study into usable takeaways. Some days it's harder than others.

Enter the beer. This part of the show is an exploration of the emerging sector of craft beverages and entrepreneurship in Boulder, Colorado. Also, sampling drinks makes the podcast more approachable, candid and entertaining, with the hope that we'll provide at least one takeaway from the paper for the entrepreneurs who listen.

Now in our third season, we have visited countless distilleries, wineries and breweries, tackling the most unlikely pairings of tastings and topics: Pinot Noir with research on the transformation of the yoga industry; a rice-based vodka with a paper on rural ventures; malt whiskey with research on hierarchies within cooperatives; and a hazy India Pale Ale with a study on Cannabis' influence on new venture ideation.

With 20+ episodes, over 1,400 downloads and 2,000+ listeners, we are encouraged by the podcast's growth since our first episode in 2020. Scholars tell us they really like what we're trying to do with the podcast, and students say they enjoy the discussions and how it makes the research more approachable.

And everyone, it appears, loves learning about beer and spirits.

"Creative Distillation" is available on Spotify, Apply Podcasts and Soundcloud. Find descriptions of the podcast and episodes here: leeds.ly/creative-dist(http://leeds.ly/creative-dist)

\section{Listen}

"Creative Distillation" discusses Brewdog Beer and Founder Authenticity

Link to video

Creative Distillation(https://soundcloud.com/creativedistillation) - EP14: Brewdog Beer and Founder Authenticity(https://soundcloud.com/creative-distillation/ ep14-brewdog-beer-and-founder-authenticity) 